\title{
Pengaruh Praktek Manajemen Pada Nurse Satisfaction Serta Dampaknya Terhadap Nurse Loyalty Di Era Pandemi Covid-19 (Studi Empiris Pada Rumah Sakit Swasta XYZ di Jakarta)
}

\author{
Reno Prananditya Ashaf, Ferdi Antonio \\ Universitas Tarumanagara, Jakarta, Indonesia \\ Universitas Pelita Harapan, Jakarta, Indonesia \\ renoashaf@gmail.com
}

\begin{abstract}
ABSTRAK
Tenaga perawat merupakan tenaga kesehatan yang sangat krusial dalam berlangsungnya suatu pelayanan kesehatan di rumah sakit. Namun terdapat banyak faktor penyulit yang muncul di era pandemi Covid-19 yang menuntut manajemen rumah sakit untuk lebih adaptif dalam mengelola tenaga perawat di rumah sakit.. Penelitian ini bertujuan untuk menguji anteseden dari satisfaction yaitu healthcare planning, healthcare organizing, healthcare staffing, healthcare leading, dan healthcare controlling terhadap nurse loyalty di rumah sakit dalam situasi pandemi Covid-19. Data empiris yang di analisis dalam penelitian ini diperoleh dari rumah sakit XYZ. Sampel diperoleh menggunakan probability sampling yang memperoleh 204 data responden melalui kuesioner yang disebar secara online. Analisis dari data yang dikumpulkan dilakukan dengan menggunakan metode PLS-SEM. Hasil penelitian ini menunjukkan bahwa healthcare staffing, healthcare leading, dan healthcare controlling memilki pengaruh positif yang signifikan pada nurse satisfaction. Pengaruh langsung pada nurse satisfaction yang terkuat adalah healthcare staffing. Dampak positif dari nurse satisfaction terhadap nurse loyalty juga terbukti signifikan. Dengan demikian, teori kepuasan pegawai dalam pelayanan kesehatan dapat dikonfirmasi oleh penelitian ini. Model penelitian ini memiliki moderate predictive accuracy serta medium predictive relevance sehingga masih dapat dikembangkan lebih lanjut. Beberapa implikasi manajerial dapat diambil dari penelitian ini, serta rekomendasi bagi penelitian selanjutnya.
\end{abstract}

Kata kunci: nurse satisfaction, nurse loyalty, rumah sakit.

\begin{abstract}
Nurses are one of the most crucial healthcare workers in the continuity of healthcare services in a hospital. However, many complicating factors emerge during the Covid-19 pandemic that requires hospital management to be more adaptive in managing their nurses. This study aims to examine the antecedents of satisfaction, namely healthcare planning, healthcare organizing, healthcare staffing, healthcare leading, and healthcare controlling towards nurse loyalty in hospitals during the Covid-19 pandemic. The empirical data analyzed in this study were obtained from $X Y Z$ Hospital. The sample was obtained using probability sampling which gathered 204 respondent data through online questionnaires. The analysis of the data collected was carried using the PLS- SEM method. The results of this study indicate that healthcare staffing, healthcare leading, and healthcare controlling have a significant positive effect on nurse satisfaction. Healthcare staffing showed the strongest direct influence on nurse satisfaction. The positive impact of nurse satisfaction on nurse loyalty is also proved significantly. Thus, the theory of employee satisfaction in health services can be confirmed by this study. This research model has moderate predictive accuracy and medium predictive
\end{abstract}


Jurnal Manajemen Dan Administrasi Rumah Sakit Indonesia

E-ISSN: 2865-6583

Vol. 5 No 2, Oktober 2021

P-ISSN: 2865-6298

relevance so that it can still be developed further. Several managerial implications can be drawn from this research, as well as recommendations for further research.

Keywords: nurse satisfaction, nurse loyalty, hospital.

\section{PENDAHULUAN}

Pada tahun 2021, tercatat bahwa penduduk Indonesia mencapai 270,2 juta jiwa, dengan rata-rata laju pertumbuhan penduduk sebesar 1,25 persen dengan tingkat kepadatan tertinggi sebesar $56,1 \%$ dari total penduduk berada di Pulau Jawa (Badan Pusat Statistik, 2021). Dari seluruh penduduk Indonesia, 70,72\% merupakan penduduk yang masuk dalam golongan usia produktif dengan rentang usia $15-64$ tahun (BPS, 2021). Hal ini menjelaskan bahwa Indonesia masih dalam kondisi bonus demografi, dimana penting bagi negara untuk menjaga kualitas penduduk agar tetap produktif dengan memenuhi kebutuhan-kebutuhan dasar, terutama dalam bidang kesehatan. Fasilitas kesehatan memegang peranan penting dalam menjaga produktivitas masyarakat, terutama rumah sakit (Saralita \& Ardiyanti, 2020). Hal ini menuntut manajemen rumah sakit untuk dapat terus berkembang dalam menghadapi perubahan-perubahan eksternal yang dapat terjadi (PERSI, 2020).

Rumah sakit merupakan pelayanan kesehatan yang menyediakan jada pelayanan rawat inap, rawat jalan, dan gawat darurat yang merupakan badan usaha dengan sumber daya yang beragam, kebutuhan teknologi yang terdepan, dan kaya akan baik konflik internal maupun eksternal (Adisasmito, 2008). Di Indonesia, rumah sakit dibagi menjadi rumah sakit berdasarkan jumlah fasilitas (Menteri Kesehatan, 2020), jenis pelayanan yang diberikan, status akreditasi (Bossert, Kosen, Harsono, \& Gani 1997), dan jenis kepemilikiannya (Adisastmito, 2008). Berdasarkan kepemilikiannya, rumah dibagi menjadi rumah sakit kepemilikan swasta, dan kepemilikan pemerintah. Rumah sakit swasta merupakan jenis rumah sakit yang mengalami perkembangan pesat di Indonesia, khususnya di DKI Jakarta, yang merupakan hampir $30 \%$ dari jumlah total rumah sakit. Oleh karena itu, kinerja rumah sakit swasta secara langsung dapat mempengaruhi kulaitas pelayanan kesehatan di skala nasional (PERSI, 2016).

Baik atau buruknya suatu kualitas pelayanan di rumah sakit berpusat pada sumber daya manusia yang berperan di dalam sistem rumah sakit itu sendiri. Di seluruh dunia, sekitar $50 \%$ tenaga kesehatan merupakan tenaga perawat (WHO, 2016), dan di Indonesia 60-70\% dari keseluruhan sumber daya manusia di rumah sakit merupakan tenaga perawat (Dewi, Januraga, \& Suarjana, 2020). Dengan demikian, perawat merupakan salah satu ujung tombak dari fasilitas pelayanan kesehatan dan memegang pernanan penting bagi rumah sakit untuk dapat menjaga produktifitas dan kualitasnya.

Namun, ketersediaan tenaga perawat masih merupakan tantangan bagi manajemen rumah sakit. Selain distribusi yang tidak merata (Gunawan, 2016), hal ini terjadi akibat tingginya turnover intention dari tenaga perawat di dunia. Tingkat turnover perawat di dunia mencapai 15$44 \%$ dan di Indonesia sendiri masih mencapai 5-10\% per tahun (WHO, 2016). Keadaan ini dapat terjadi akibat rendahnya tingkat loyalitas (loyalty) perawat terhadap 
rumah sakit tempat ia bekerja (Bae \& Kim, 2019). Fenomena ini dapat menjadi dorongan bagi manajemen rumah sakit dalam mengerahkan kemampuannya dalam mengelola sumber daya perawat agar kualitas pelayanan rumah sakit tetap terjaga.

Job loyalty merupakan suatu dampak yang terjadi akibat rasa puas seseorang terhadap pekerjaannya (job satisfaction) (Akbar, 2020; Dewi et al., 2020). Aspek ini penting dalam upaya peningkatan kualitas pelayanan, kepuasan pasien, dan retensi tenaga perawat di sebuah rumah sakit (Boamah, Laschinger, Wong, \& Clarke, 2018). Peran serta fungsi manajemen rumah sakit terhadap job satisfaction dari perawat juga merupakan hal yang penting. Persepsi tentang bagaimana suatu pegawai atau tenaga kerja menilai manajemen dalam menjalankan tugas dan tanggung jawabnya dapat secara langsung mempengarushi tingkat kepuasan kerja seseorang (Mita \& Maulana, 2020). Dengan demikian, penting bagi manajemen rumah sakit untuk memperhatikan job satisfaction dan job loyalty dengan menerapkan fungsifungsi manajemen dengan baik.

Pada tanggal 2 Maret 2020, Covid-19 pertama kali dilaporkan di Indonesia (WHO, 2021). Wabah ini lalu segera berkembang secara pesat dengan pusat persebaran di DKI Jakarta mencapai jumlah per kapita 0,75 per 1.000 orang (Olivia, Gibson, \& Nasrudin, 2020). Keadaan pandemi ini berdampak pada beban finansial yang harus di lalui oleh berbagai fasilitas kesehatan, terutama rumah sakit dan secara langsung berdampak pada peningkatan kompleksitas dalam pengelolaan sumber daya manusia di rumah sakit, khususnya tenaga perawat. Pandemi Covid-19 secara langsung berperan sebagai faktor penyulit dari tantangan rumah sakit dalam mengelola tingkat turnover dari pasien, yang sudah merupakan tantangan bagi rumah sakit di masa normal.

Berdasarkan studi terdahulu, keadaan pandemic dapat menyebabkan perubahanperubahan pola yang terjadi di rumah sakit. Pertama, jumlah pasien yang datan gke unit rawat jalan cenderung menurun akibat adanya perasaan takut yang muncul dari pasien untuk berkunjung secara langsung ke fasilitas kesehatan akibat takut tertular baik oleh sesame pasien ataupun petugas kesehatan (Prabowo et al., 2020). Hal ini juga terjadi di Amerika Serikat, dimana terjadi penurunan jumlah pelayanan di beberapa instalasi rumah sakit hingga $60 \%$ (Jeffery et al., 2020). Kedua, keadaan pandemi mengubah beban rumah sakit dari pelayanan kesehatan akut menjadi perawatan intensif, sehingga terjadi peningkatan biaya yang harus di kerahkan oleh rumah sakit (Caroll \& Smith, 2020). Ketiga, terjadinya dampak negatif bagi tenaga kesehatan akibat stress dan masalah psikologis lainnya disaat pandemi terjadi (Bai \& Zare, 2020). Oleh karena itu, para manajer di rumah sakit perlu melakukan adaptasi yang cukup signifikan seiring dengan terjadinya pandemi.

Penelitian ini difokuskan kepada rumah sakit XYZ yang merupakan rumah sakit swasta tipe C di DKI Jakarta yang berdiri sejak tahun 1965 . Rumah sakit ini merupakan rumah sakit dengan ukuran relatif besar dengan 127 jumlah tempat tidur dengan segmen pasar menengah kebawah, dimana $87,2 \%$ dari pasien merupakan pasien BPJS. Berbeda dengan rumah sakit pada umumnya, di era pademi Covid-19 ini pada tahun 2020 jumlah pasien 
mengalami peningkatan pesat dengan total pasien 98.418 orang. Peningkatan yang terjadi adalah sekitar 12.000 pasien rawat jalan bila dibandingkan dengan tahun sebelumnya. Bed occupancy rate (BOR) dari rumah sakit di tahun 2020 mencapai 97,5\% selama pandemi. Namun seiring dengan peningkatan pasien, terdapat tiga fenomena yang muncul berdasarkan data internal rumah sakit. Pertama, terjadinya peningkatan permintaan mutasi perawat di unit rawat jalan mencapai lima kali lipat dibandingkan tahun sebelumnya. Kedua, terjadinya peningkatan jumlah komplain yang diajukan oleh pasien terhadap perawat, dengan peningkatan jumlah komplain mencapai $80 \%$ dibandingkan dengan tahun sebelumnya. Ketiga, peningkatan jumlah permintaan cuti diluar tanggungan oleh tenaga perawat, hingga lebih dari tiga kali lipat. Uraian diatas adalah alasan mengapa rumah sakit XYZ menarik untuk diteliti di masa pandemi Covid-19, dengan munculnya fenomena fenomena yang berhubungan dengan tingkat satisfaction, loyalty, dan kualitas pelayanan dari perawat.

Posisi penelitian ini dilakukan dengan mengadopsi model penelitian terdahulu oleh Hossain, Kiumarsi, Yahya, \& Hashemi (2019) dengan mengubah variabel physician satisfaction dan physician loyalty menjadi nurse satisfaction dan nurse loyalty dengan tujuan untuk menyesuaikan hasil penelitian yang diambil berdasarkan perspektif perawat. Penelitian ini menguji pengaruh dari lima variabel independen healthcare planning, healthcare organizing, healthcare staffing, healthcare leading, dan healthcare controlling terhadap nurse loyalty sebagai variabel dependenm, melalui nurse satisfaction sebagai variabel mediasinya. Model penelitian ini akan diuji secara empiris pada tenaga perawat yagn aktif bekerja di rumah sakit XYZ selama pandemic Covid-19 berlangsung. Hasil penelitian ini diharapkan dapat memberikan implikasi manajerial dalam upaya meningkatkan kinerja pelayanan di rumah sakit.

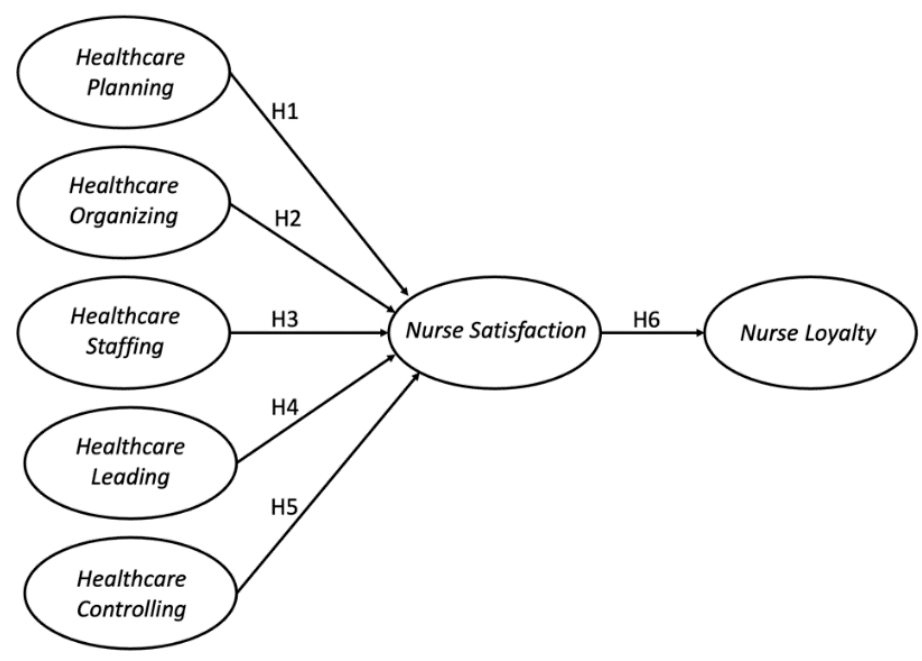

Gambar 1 Model Penelitian

Sumber: Adopsi dari Hossain et al. (2019) 
Definisi konseptiual dan operasionalisasi dari variabel-variabel penelitian ini, beserta suymbernya dirangkum dalam tabel di bawah ini:

Tabel 1 Definisi Konseptual dan Operasionalisasi Variabel

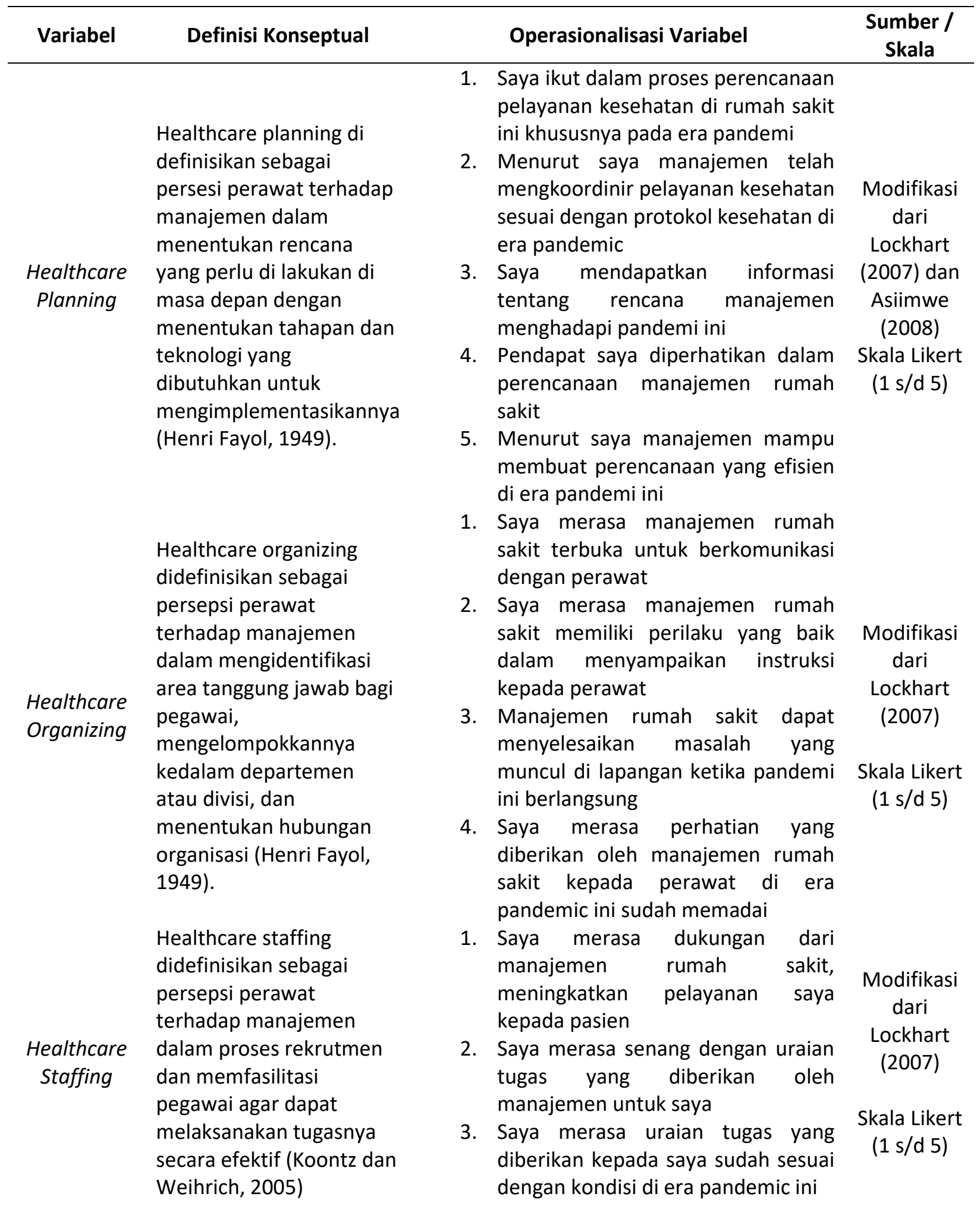


Healthcare Leading

Healthcare Controlling

Nurse Satisfaction

Nurse Loyalty
Healthcare leading didefinisikan sebagai persepsi perawat terhadap manajemen dalam

mengharmonisasikan dan memimpin kegiatankegiatan untuk mencapai tujuan dari organisasi serta menjaga komunikasi yang baik dengan pegawai (Henri Fayol, 1949).

Healthcare controlling didefinisikan sebagai persepsi perawat terhadap manajemen dalam melakukan evaluasi performa personel dan membandingkannya dengan rencana yang sudah ditentukan (Henri Fayol, 1949)

Nurse satisfaction pada penelitian ini didefinisikan sebagai perasaan positif tenaga perawat yang muncul atas penilaian mereka terhadap pengalaman kerja nya, atas kondisi pekerjaan yang dapat memenuhi keinginan dan kebutuhannya (Liu et al., 2016).

Pada penelitian ini, nurse loyalty didefinisikan sebagai keyakinan yang kuat oelh perawat terhadap nilai-nilai dan
4. Menurut saya pengembangan keterampilan perawat merupakan hal penting yang perlu diperhatikan oleh manajemen rumah sakit

1. Saya merasa manajemen di rumah sakit ini bersifat fleksibel di era pandemic ini

2. Di rumah sakit ini saya banyak mendapatkan pelajaran baru dari atasan atau supervisor saya

3. Saya merasa gaya kepemimpinan di rumah sakit ini berpengaruh positif pada pelayanan yang saya berikan

4. Menurut saya manajemen rumah sakit sudah dapat menangkap peluang untuk pengembangan rumah sakit di masa pandemi ini

1. Saya tidak merasa terbebani atau terhambat oleh sistem pengawasan di rumah sakit ini

2. Menurut saya kontrol manajemen pada tenaga kesehatan di rumah sakit ini (khususnya di era pandemi) sudah berlangsung sesuai dengan protokol kesehatan

Modifikasi dari Lockhart (2007) dan Asiimwe (2008) Skala Likert (1 s/d 5)

Modifikasi dari Lockhart (2007)

3. Pengawasan manajemen rumah sakit ini mendorong saya menjadi patuh terhadap peraturan

Skala Likert (1 s/d 5)

4. Saya dapat menerima fungsi kontrol yang di lakukan oleh manajemen rumah sakit di era pandemi ini

1. Secara umum saya puas dengan pekerjaan saya di rumah sakit ini

2. Menurut saya kompensasi yang diberikan oleh rumah sakit ini sudah sesuai dengan harapan saya

3. Saya merasa pekerjaan sebagai perawat di rumah sakit ini sudah berjalan seperti yang saya harapkan

4. Saya menyukai pekerjaan saya sebagai perawat di rumah sakit ini

Modifikasi dari Lockhart (2007)

Skala Likert (1 s/d 5)

5. Rumah sakit ini adalah pilihan utama saya untuk bekerja

1. Saya berbicara positif mengenai tempat kerja saya saat saya berbicara dengan pasien

Modifikasi dari Lockhart

2. Saya berbicara positif mengenai (2007) tempat kerja saya saat saya 


tujuan organisasi,
sehingga menimbulkan
kemauan untuk
mengerahkan upaya yang
signifikan atas nama
organisasi dan keinginan
yang kuat untuk
mempertahankan
keanggotaan dalam
organisasi. (Mowday,
Porter, dan Steers, 1979).

tujuan organisasi, sehingga menimbulkan kemauan untuk mengerahkan upaya yang signifikan atas nama organisasi dan keinginan yang kuat untuk keanggotaan dalam Porter, dan Steers, 1979). berbicara dengan kerabat atau keluarga

3. Saya merekomendasikan rumah sakit ini ke orang lain

4. Saya tetap ingin untuk melanjutkan kerja saya di tempat ini di masa depan

5. Saya belum terpikir untuk pindah bekerja ke rumah sakit lain dalam waktu dekat

6. Saya tidak akan berpindah tempat kerja secara langsung apabila mendapatkan tawaran pekerjaan di rumah sakit lain

Sumber: Hasil Olahan Data Penelitian (2021)

\section{METODE}

Populasi pada penelitian ini merupakan seluruh tenaga perawat yang secara aktif bekerja di rumah sakit XYZ. Berdasarkan jumlah populasi yang sudah diketahui, penelitian ini menentukan jumlah sampel dengan menggunakan tabel yang diformulasikan oleh Krecjie dan Morgan (1970) dengan jumlah populasi $\mathrm{N}=342$, maka dibutuhkan sampel minimal sejumlah $\mathrm{n}=181$. Berikutnya, berdasarkan Kock dan Hadaya (2019), dalam pengunaan metode partial least square - structural equation modelling (PLS-SEM) dibutuhkan sampel minimal sejumlah 160 responden yang diperoleh berdasarkan metode perhitungan akar kuadrat terbalik (inverse square root method) guna memberikan hasil optimal. Dari seluruh kuesioner yang tersebar, didapatkan 204 responden yang memenuhi syarat penelitian dan jumlahnya sudah melebihi kebutuhan sampel minimal berdasarkan kedua parameter yang sudah disebutkan. Metode pengambilan sampel yang dilakukan dalam penellitian ini menggunakan metode probability sampling dengan teknik simple random sampling. Kuesioner dibentuk menggunakan skala Likert 1-5, yang disebarkan secara online dengan membagikan link yang dapat diisi secara suka rela kepada 342 orang yang berada di dalam sampling frame penelitian ini.

Dalam penelitian ini, analisis multivariate adalah metode analisis data yang digunakan. Metode ini dipilih atas dasar variabel laten atau konstruk dalam penelitian ini cukup kompleks (Sekaran \& Bougie, 2016). Terdapat tujuh variabel dengan enam jalur (path) dan satu variabel mediasi, sehingga penelitian ini membutuhkan metode analisis yang dapat dilakukan secara serentak untuk dapat melihat pengaruh antar variabel variabel tersebut. Selanjutnya dilakukan analisis multivariate berbasis variance dengan menggunakan partial least square structural equation modelling (PLS-SEM). Metode ini digunakan dengan alasan bahwa sifat analisis dari metode penelitian ini bersifat exploratory, kemampuan explanatory dan prediction dari model 
penelitian ini merupakan salah satu objektif dari apa yang ingin diteliti, dan input data yang digunakan pada penelitian tidak terdistribusi secara normal. Berdasarkan hal tersebut, maka metode PLS-SEM merupaakn metode yang tepat untuk digunakan dalam penelitian ini (Hair et al, 2017). Metode PLS-SEM pada penelitian ini menggunakan aplikasi SmartPLS ${ }^{\mathrm{TM}}$ versi 3.3.3. Pada kalkulasi PLS-SEM terdapat dua hasil model yang dapat di gunakan didalam penelitian dimana masing-mangsing model digunakan untuk menguji realibilitas dan validitas dari indikator yang digunakan dan menilai kualitas dari model dalam penelitian. Hal ini secara bertahap didapatkan melalui hasil uji outer model dan inner model. Pada uii analisis penelitian ini juga dilakukan uji signifikansi dari pengaruh antar konstruk serta analaisis koefisiennya.

\section{HASIL}

Berdasarkan kuesioner yang disebar, didapatkan 204 responden dengan gambaran profil sebagai berikut:

Tabel 2 Profil Demografi Responden

\begin{tabular}{|c|c|c|c|}
\hline Deskripsi & Kategori & Jumlah & Persentase (\%) \\
\hline \multirow{7}{*}{ Usia } & $<20$ tahun & 0 & 0 \\
\hline & $20-25$ tahun & 85 & 42 \\
\hline & $26-30$ tahun & 87 & 43 \\
\hline & $31-40$ tahun & 28 & 14 \\
\hline & $41-50$ tahun & 3 & 1 \\
\hline & $>50$ tahun & 1 & 0 \\
\hline & Total & 204 & 100 \\
\hline \multirow{3}{*}{ Jenis Kelamin } & Pria & 17 & 8 \\
\hline & Wanita & 187 & 92 \\
\hline & Total & 204 & 100 \\
\hline \multirow{7}{*}{$\begin{array}{l}\text { Pendidikan } \\
\text { Terakhir }\end{array}$} & SMA/ Sederajat & 4 & 2 \\
\hline & Diploma & 147 & 72 \\
\hline & Profesi Ners & 11 & 5 \\
\hline & $\mathrm{S} 1$ & 35 & 17 \\
\hline & S2 & 4 & 2 \\
\hline & Lainnya & 3 & 1 \\
\hline & Total & 204 & 100 \\
\hline \multirow{7}{*}{ Domisili } & DKI Jakarta & 146 & 72 \\
\hline & Bekasi & $\begin{array}{c}140 \\
24\end{array}$ & 12 \\
\hline & Depok & 18 & 9 \\
\hline & Bogor & 9 & 4 \\
\hline & Lainnya & 4 & 2 \\
\hline & Tangerang / Tangerang & 3 & 1 \\
\hline & $\begin{array}{l}\text { Selatan } \\
\text { Total }\end{array}$ & 204 & 100 \\
\hline \multirow{3}{*}{$\begin{array}{l}\text { Lama bekerja } \\
\text { sebagai perawat }\end{array}$} & $<1$ tahun & 30 & 15 \\
\hline & $1-3$ tahun & 73 & 36 \\
\hline & $4-6$ tahun & 63 & 31 \\
\hline
\end{tabular}




\begin{tabular}{|c|c|c|c|}
\hline & 7 - 10 tahun & 24 & 12 \\
\hline & $>10$ tahun & 14 & 7 \\
\hline & Total & 204 & 100 \\
\hline & $<1$ tahun & 42 & 21 \\
\hline & 1 - 3 tahun & 82 & 40 \\
\hline Lama bekerja di & $4-6$ tahun & 57 & 28 \\
\hline RS XYZ & $7-10$ tahun & 19 & 9 \\
\hline & $>10$ tahun & 4 & 2 \\
\hline & Total & 204 & 100 \\
\hline & Penuh waktu (full time) & 144 & 71 \\
\hline Status & Paruh waktu (part time) & 44 & 22 \\
\hline kepegawaian & Lainnya & 16 & 8 \\
\hline & Total & 204 & 100 \\
\hline & Bangsal perawatan & 64 & 31 \\
\hline & Kamar operasi / & 30 & 15 \\
\hline & tIndakan medis & 26 & 13 \\
\hline Penenempatan di & $\begin{array}{l}\text { Polıklınık } \\
\text { Unit }\end{array}$ & 19 & 9 \\
\hline RS XYZ & Unit gawat darurat & 15 & 7 \\
\hline & ICU / ICCU / HCU & 5 & 2 \\
\hline & Lainnya & 45 & 22 \\
\hline & Total & 204 & 100 \\
\hline Pernah terpapar & Tidak pernah & 176 & 86 \\
\hline COVID-19 & Pernah & 28 & 14 \\
\hline & Total & 204 & 100 \\
\hline
\end{tabular}

Sumber: Hasil Olahan Data Penelitian (2021)

Berdasarkan tabel diatas, didapatkan hampir seluruh responden berada pada rentang usia 20-40 tahun. hal ini menggambarkan bahwa tenaga perawat di RS XYZ masih dalam usia produktif, dan dapat diperkirakan bahwa responden masih aktif dalam meniti karir. Hampir seluruh responden memiliki jenis kelamin perempuan. Mayoritas dari responden memiliki latar belakang pendidikan diatas SMA, oleh karena itu pada responden dianggap dapat memahami isi kuesioner dan dapat menjawab dengan baik. $72 \%$ domisili responden berada di DKI Jakarta sehingga secara subjektif responden dapat membandingkan kinerja rumah sakit $\mathrm{XYZ}$ dengan rumah sakit lainnya yang berada di
DKI Jakarta. 51\% responden memiliki pengalaman kerja dibawah 3 tahun, hal ini dapat dianggap bahwa masih banyak responden yang pandangannya terhadap manajemen rumah sakit masih belum matang dan fokus pekerjaan hanya sebatas praktisi. Dari seluruh responden, 61\% memiliki pengalaman kerja di RS XYZ kurang dari 3 tahun, dimana responden dianggap masih belum dapat secara akurat mengenali budaya atau culture yang terdapat di rumah sakit dan secara objektif menilai manajemen rumah sakit. Berdasarkan penempatan kerja, tampak bahwa responden berasal dari beragam departemen sehingga menandakan bahwa data responden diharapkan dapat 
mewakilkan seluruh perawat di rumah dianggap cukup homogen sehingga hasil sakit. Selama berlangsungnya pandemi, didapatkan $86 \%$ responden belum pernah terpapad oleh Covid-19, dimana hal ini memberikan gambaran bahwa kondisi emosi dan psikologis dari responden pengisian kuesioner dapat menggambarkan bagaimana perspektif responden terhadap fungsi manajemen rumah sakit tepat di era pandemi Covid-19.

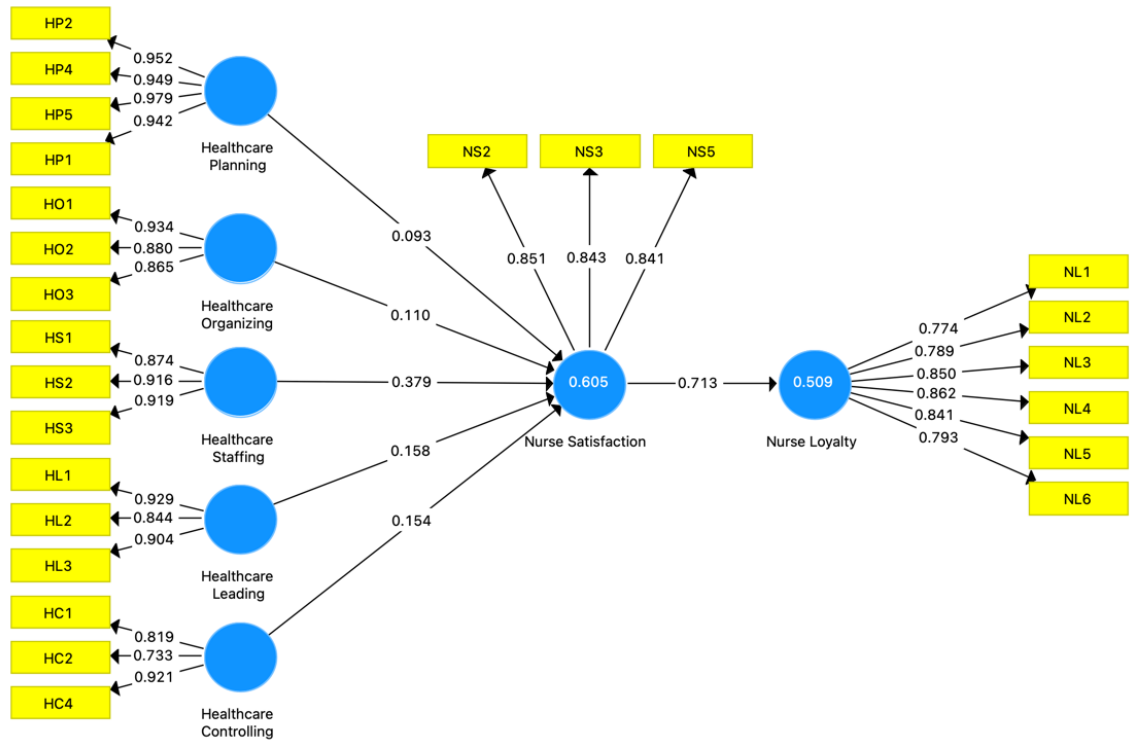

Gambar 2 Hasil Outer Model Penelitian

Sumber: Hasil Olahan Data Penelitian (2021)

Hasil uji outer model reflective pada penelitian ini tersusun atas 4 bagian, yaitu indicator reliability (outer loading), construct reliability (Cronbach's alpha dan composite reliability), construct validity (average variance extracted atau AVE), dan discriminant validity. Pada output outer model, 25 indikator dari 32 indikator reflektif diikutsertakan dalam penelitian ini. Mengacu pada gambar outer model tersebut, seluruh indikator sudah dinyatakan reliabel untuk mengukur konstruknya sesuai dengan acuan outer loading yang diyaratkan oleh Hair et al. (2019). 


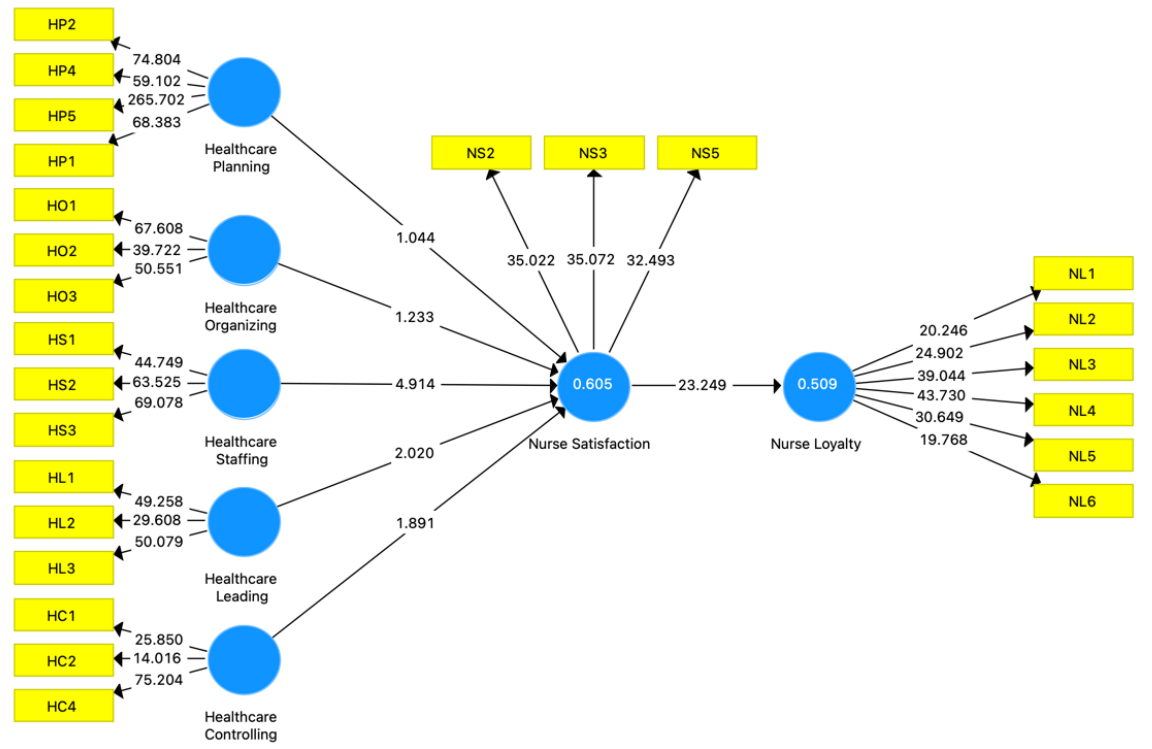

Gambar 3 Hasil Inner Model Penelitian

Sumber: Hasil Olahan Data Penelitian (2021)

Berdasarkan hasil uji inner model pada penelitian ini, didapatkan beberapa hasil yang dapat menentukan kualitas model penelitian. Pertama, tidak terdapat adanya masalah multikolinearitas antar variabel dalam model penelitian ini dan kualitas model penelitian acceptable dalam isu multikolinearitas, Hal ini ditentukan oleh nilai inner variance inflation factor (VIF) semua variabel penelitian kurang dari 3. Kedua, didapatkan bahwa variabel nurse loyalty memiliki nilai $\mathrm{R}^{2}=0,509$ yang menjelaskan bahwa variabel nurse loyalty dapat dijelaskan sebesar $50 \%$ oleh variabelvariabel independentnya didalam penelitian ini dan sisanya dapat dijelaskan oleh variabel di luar penelitian. Hal ini juga menjelaskan bahwa model penelitian memiliki moderate predictive accuracy dalam memprediksi variabel dependen nurse loyalty. Ketiga, dari hasil uji f-squared didapatkan bahwa semua variabel independent memiliki small effect size dengan nilai dibawah 0,15 terhadap nurse satisfaction. Namun, didapatkan bahwa nurse satisfaction memiliki large effect size terhadap nurse loyalty dengan $f^{2}=1,037$. Keempat, model penelitian ini memiliki nilai $Q$-squared sebesar 0,333 , yang menandakan bahwa kemampuan predictive relevance dari model penelitian ini masuk dalam kategori moderate.

Tabel 3 Hasil Uji Hipotesis

\begin{tabular}{cccccc} 
No & Path & $\begin{array}{c}\text { Standardized } \\
\text { Coefficient }\end{array}$ & T-Statistics & Signifikansi & Hasil \\
\hline H1 $\begin{array}{l}\text { Healthcare Planning -> } \\
\text { Nurse Satisfaction } \\
\text { Healthcare Organizing - }\end{array}$ & 0,093 & 1,044 & Tidak Signifikan & $\begin{array}{c}\text { Hipotesis tidak } \\
\text { didukung }\end{array}$ \\
> Nurse Satisfaction & 0,11 & 1,233 & Tidak Signifikan & $\begin{array}{c}\text { Hipotesis tidak } \\
\text { didukung }\end{array}$
\end{tabular}


Jurnal Manajemen Dan Administrasi Rumah Sakit Indonesia

E-ISSN: 2865-6583

Vol. 5 No 2, Oktober 2021

P-ISSN: 2865-6298

\begin{tabular}{|c|c|c|c|c|c|}
\hline H3 & $\begin{array}{l}\text { Healthcare Staffing -> } \\
\text { Nurse Satisfaction }\end{array}$ & 0,379 & 4,914 & Signifikan & $\begin{array}{l}\text { Hipotesis } \\
\text { didukung }\end{array}$ \\
\hline $\mathrm{H} 4$ & $\begin{array}{l}\text { Healthcare Leading -> } \\
\text { Nurse Satisfaction }\end{array}$ & 0,158 & 2,02 & Signifikan & $\begin{array}{l}\text { Hipotesis } \\
\text { didukung }\end{array}$ \\
\hline H5 & $\begin{array}{l}\text { Healthcare Controlling } \\
\text {-> Nurse Satisfaction }\end{array}$ & 0,154 & 1,891 & Signifikan & $\begin{array}{l}\text { Hipotesis } \\
\text { didukung }\end{array}$ \\
\hline H6 & $\begin{array}{l}\text { Nurse Satisfaction-> } \\
\text { Nurse Loyalty }\end{array}$ & 0,713 & 23,249 & Signifikan & $\begin{array}{l}\text { Hipotesis } \\
\text { didukung }\end{array}$ \\
\hline
\end{tabular}

Sumber: Hasil Olahan Data PLS-SEM Penelitian (2021)

Berdasarkan tabel uji hipotesis, didapatkan bahwa keenam hipotesis memiliki nilai standard coefficient dengan nilai positif yagn sesuai dengan arah pada hipotesis yang diajuan didalam penelitian. Namun, hanya empat dari enam hipotesis terbukti memiliki pengaruh yang signifikan dengan nilai T-Statistics lebih tinggi dari nilai Ttable 1,645. Dua diantara keenam hipotesis dinyatakan tidak signifikan dengan nilai Tstatistics berada dibawah nilai T-table.

Setelah dilakukan uji hipotesis, dilakukan analisis jalur atau path menggunakan uji specific indirect effect dengan hasil bahwa pengaruh paling kuat ada pada jalur healthcare staffing menuju ke nurse loyalty melalui nurse satisfaction dengan nilai standardized coefficient 0,279.

Pada hasil Importance-Performance Map Analysis (IPMA) didapatkan bahwa healthcare staffing merupakan hal yang paling penting berdasarkan perspektif perawat dalam mempengaruhi nurse satisfaction. Dan melalui uji IPMA indicators, didapatkan bahwa seluruh indikator healthcare staffing masuk kedalam indikator terpenting dan sudah memiliki performa yang baik bagi perawat.

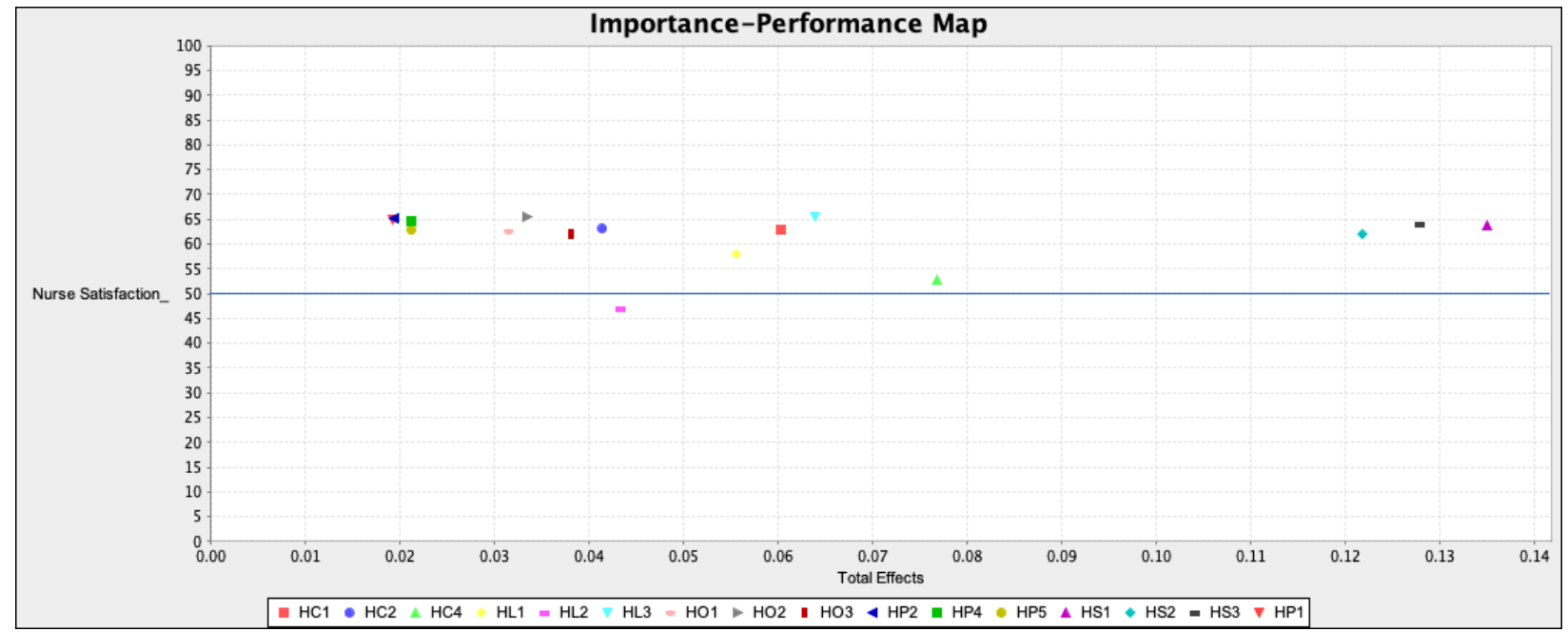

Gambar 4 Hasil IPMA Indicator

Sumber: Hasil Olahan Data Penelitian (2021) 


\section{PEMBAHASAN}

Penelitian ini ditujukan untuk menguji model penelitian secara empiris mengenai bagaimana pengaruh praktek manajemen pada nurse satisfaction dan dampaknya pada nurse loyalty di era pandemic Covid19. Model penelitian ini diadopsi dari

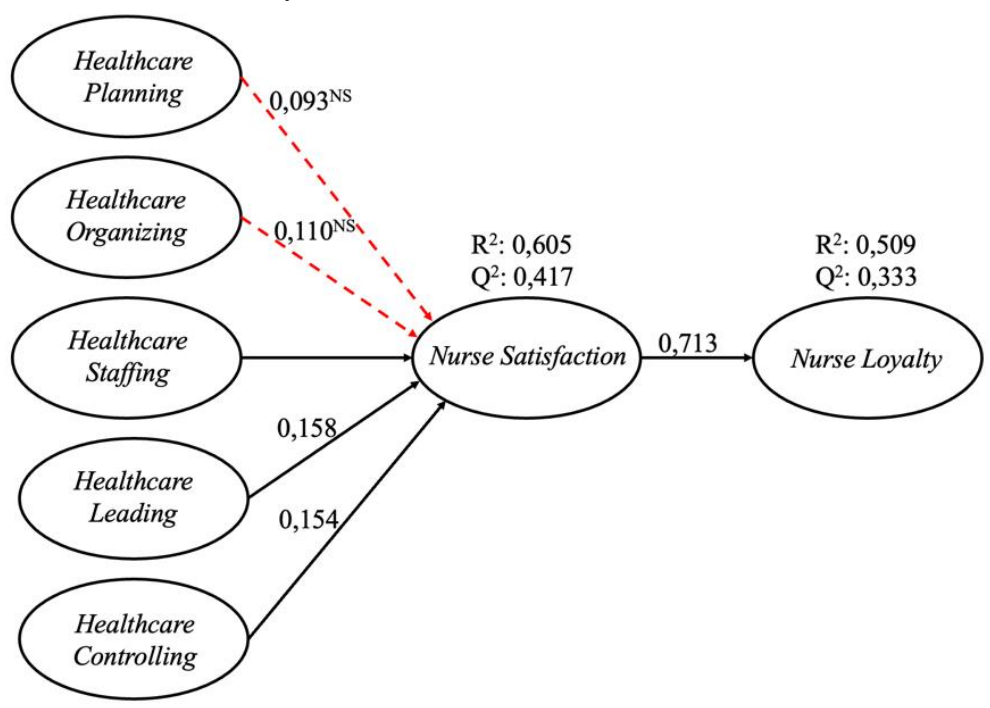

Gambar 5 Gambar Model Hasil (Empirical Model)

Sumber: Hasil olahan data penelitian (2021)

Nurse satisfaction memiliki pengaruh
Berdasarkan nilai standardized coefficient dari setiap jalur dapat dinyatakan bahwa keenam jalur memiliki pengaruh positif sesuai dengan arah hipotesis. Namun dari keenam jalur tersebut, hanya terdapat empat jalur yang pengaruhnya terbukti secara signifikan. Sehingga pada penelitian ini, terdapat empat hipotesis yang didukung (supported). Dari analisis model struktural didapatkan nilai R-squared dan Q-squared pada variabel dependen nurse loyalty dan variabel mediasi nurse satisfaction menunjukkan bahwa model ini memiliki moderate predictive accuracy dan medium predictive relevance. Dengan demikian, kemampuan explanatory dan prediction dari model penelitian masih dapat di tingkatkan. model penelitian terdahulu oleh Hossain et al. (2019) dengan dilakukannya penyesuaian variabel dependen dan mediasi menjadi nurse loyalty dan nurse satisfaction. Dalam penelitian ini dilakukan metode analisis PLS-SEM dengan gambar model hasil atau empirical model sebagai berikut.

\section{positif yang signifikan terhadap nurse} loyalty. Berdasarkan nilai $f$-squared yang didapatkan bahwa nurse satisfaction memiliki effect size yang besar terhadap nurse loyalty. Hal ini sejalan dengan penelitian sebelumnya yang menyatakan bahwa job satisfaction memiliki pengaruh positif pada employee loyalty (Dhir et al., 2020; Hossain et al., 2019; Arshad dan Mansood, 2013). Hal ini menekankan bnahwa rumah sakit perlu melakukan monitor dan evaluasi tingkat kepuasan dari perawat untuk dapat menurunkan turnover intention dari perawat, serta memusatkan perhatian pada faktor-faktor yang secara langsung mempengaruhi nurse satisfaction.

Berdasarkan hasil uji hipotesis, dari beberpaa faktor yang terbukti memiliki 
pengaruh positif terhadap nurse satisfaction, healthcare staffing memiliki pengaruh positif terbesar dengan nilai standardized coefficient tertinggi sebesar 0,379 . Hal ini sejalan dengan temuan pada hasil IPMA construct yang menjelaskan bahwa dari sudut pandang perspektif perawat, staffing merupakan hal yang paling penting dalam mempengaruhi nurse satisfaction. Healthcare staffing juga memiliki hasil specific indirect effect tertinggi terhadap nurse loyalty melalui nurse satisfaction. Temuan ini sejalan dengan penelitian empiris terdahulu (Hossain et al., 2019; Kalisch \& Lee, 2014; Lu et al., 2015).

Berdasarkan hasil uji IPMA indicator, dari beberapa indikator yang mengukur variabel healthcare staffing tampak bahwa berdasarkan perspektif tenaga perawat, dukungan moral yang ditujukan terhadap perawat dapat meningkatkan pelayanan terhadap pasien, dan penentuan uraian tugas sesuai dengan minat dan kompetensi perawat. Keadaan pandemic dapat dinilai sebagai keadaaan diluar kebiuasaan normal, dimana banyak terjadi perubahan kebiasaan baik pada tingkat manajerial, hingga para petugas di lapangan. Pada keadaan pandemi, tenaga perawat lebih memprioritaskan keamanan kerja dan beban tugasnya sehingga staffing menjadi salah satu hal yang paling krusial dalam menentukan tingkat kepuasan dari perawat (Labrague, 2021; Lu et al., 2015). Keadaan ini membuat keterlibatan proses planning dan organizing dari perawat bukanlah sebagai prioritas, dimana tingkat trust para perawat terhadap manajemen rumah sakit lebih diutamakan dalam pengambilan keputusan di masa pandemi. Fenomena ini juga dapat dijelaskan oleh teori contingency, yang menjelaskan bahwa perubahan lingkunganm, teknologi, hingga ukuran suatu organisasi dapat mempengaruhi po9la dari suatu organisasi (Rayburn \& Gayle Rayburn, 1991). Hal ini menandakan bahwa semua sistem akan bergantung pada situasi dan tidak semua sistem dapat diberlakukan secara universal.

Temuan terakhir berdasarkan IPMA indicator didapaktan bahwa masih ada indikator yang belum memiliki performa baik, yaitu HL2 yang merupakan indikator dari healthcare leading. Berdasarkan hal tersebut, manajemen rumah sakit masih perlu memperbaiki gaya kepemimpinannya dan membentuk budaya kerja yang bersifat konstruktif, sehingga para perawat dapat memperoleh peningkatan skill dan pengetahuan dari para pimpinannya.

Temuan berikutnya adalah terdapat dua hipotesis yang tidak didukung (not supported) antara lain $\mathrm{H} 1$ dan $\mathrm{H} 2$, dimana hal ini menjelaskan bahwa pengaruh healthcare planning dan healthcare organizing terhadap nurse satisfaction tidak terbukti secara signifikan. Hal ini tidak sejalan dengan penelitian sebelumnya oleh Hossain et al. (2019) yang mendapatkan bahwa healthcare organizing memiliki pengaruh positif yang signifikan terhadap physician satisfaction. Hal ini dapat dijelaskan berdasarkan beberapa perbedaan yang ada pada penelitian ini, dimana perspektif diambil bukan berdasarkan tenaga dokter namun perawat dan waktu penelitian di lakukan di masa pandemi Covid-19.

\section{KESIMPULAN}

Penelitian ini menggunakan model penelitian yang diadopsi dari penelitian terdahulu oleh Hossain et al. (2019) dengan 
menggunakan nurse loyalty sebagai variabel dependen dan nurse satisfaction sebagai variabel pemediasi yang menjadi target construct. Dalam model penelitian ini, terdapat 6 hipotesis yang telah diuji dalam konteks tenaga perawat di rumah sakit XYZ di era pandemi Covid-19. Hal ini penting untuk diperhatikan karena perawat adalah tenaga kesehatan yang secara langsung berada di garda terdepan dan sangat penting dalam menentukan kualitas pelayanan sebuah rumah sakit. Berdasarkan analisis data menggunakan metode PLS-SEM diketahui bahwa healthcare staffing, healthcare leading, dan healthcare controlling terbukti secara signifikan mempunyai pengaruh positif pada nurse satisfaction dimana bila persepsi perawat terhadap variabelvariabel tersebut meningkat, maka nurse loyalty akan meningkat pula.

Berdasarkan analisis model struktural diketahui bahwa model penelitian pelayanan rumah sakit ini memiliki moderate predictive accuracy dengan medium predictive relevance pada variabel dependen nurse loyalty. Hal ini dapat diterima karena hanya ada satu jalur yang memprediksikan nurse loyalty yaitu satisfaction. Dengan demikian, penelitian ini masih dapat dikembangkan lebih lanjut untuk meningkatkan kemampuan prediksi model.

Pada penelitian ini dapat ditarik implikasi manajerial berupa pemberian insentif selama pandemic Covid-19 berlangsung, dengan memberikan rewards atas pencapaian key performance indicator di masa pandemic dan mengurangi beban kerja dengan mencukupi kebutuhan tenaga perawat selama pandemi. Manajemen perlu memonitor danmengevaluasi nurse satisfaction dengan memperhatikan kompensasi yang diberikan pada perawat terutama di masa pandemic, dan meyesuaikan uraian tugas yang diberikan kepada masing-masing perawat sesuai dengan minat. Manajemen perlu memprioritaskan fungsi staffing dengan memberikan pelatihan-pelatihan untuk mengembangkan skill dan melakukan performance appraisal sebagai upaya untuk mengetahui dan menyesuaikan uraian tugas yang diberikan dengan kompetensi dan minat perawat.

dengan memperhatikan faktor emosi dan psikis dari responden. Kedua, Model penelitian ini memiliki medium predictive relevance dan moderate predictive accuracy sehingga kualitas dari model penelitian masih dapat ditingkatkan. Dapat disarankan untuk melakukan pengambilan sampel dengan metode sensus untuk dapat mencakup jumlah sampel yang lebih banyak untuk meningkatkan predictive relevance dan menambah variabel-variabel yang secara langsung memprediksi nurse loyalty seperti motivasi dan psychological empowerment untuk meningkatkan predictive accuracy dari model penelitian. Ketiga, penelitian ini hanya terbatas pada rumah sakit $X Y Z$, dimana hasil penelitian dapat lebih memberikan dampak yang relevan apabila melibatkan rumah sakit swasta. 
Jurnal Manajemen Dan Administrasi Rumah Sakit Indonesia

E-ISSN: 2865-6583

Vol. 5 No 2, Oktober 2021

P-ISSN: 2865-6298

\section{DAFTAR PUSTAKA}

Adisasmito, W. (2008). Kesiapan Rumah Sakit Dalam Menghadapi Globalisasi. Case Studi: Analisis Kesehatan. Fakulatas Kesehatan Masyarakat Universitas Indonesia.

Akbar, K. A. (2020). Kepuasan Kerja Karyawan di Dinas Kesehatan Kabupaten X Provinsi Jawa Timur Saat Pandemi Covid19. Jurnal Kesehatan, 11(3), 336. https://doi.org/10.26630/jk.v11i3.1995

Asiimwe, D. (2008). Identification of priority research questions within the areas of: health financing; human resources for health and the role of non-state sector. Identification of Priority Research Questions within the Areas of Health Financing, Human Resources for Health and the Role of Non-State Sector.

Bai, G., \& Zare, H. (2020). Hospital Cost Structure and the Implications on Cost Management During COVID-19. Journal of General Internal Medicine, 35(9), 2807-2809.

https://doi.org/10.1007/s11606-02005996-8

Bae, S.-Y., \& Kim, S.-H. (2019). Convergent effects of organizational commitment, organizational loyalty, and job exhaustion on turnover intentions of some administrative administrative positions in medical institutions. Digital Convergence Research, 17(5), 303-309. https://doi.org/10.14400/JDC.2019.17.5 .303

Boamah, S. A., Spence Laschinger, H. K., Wong, C., \& Clarke, S. (2018). Effect of transformational leadership on job satisfaction and patient safety outcomes. Nursing Outlook, 66(2), 180189.

https://doi.org/10.1016/j.outlook.2017. 10.004

Bossert, T., Kosen, S., Harsono, B., \& Gani, A. (1997). Hospital autonomy in Indonesia. Boston, MA.
De los Santos, J. A., \& Labrague, L. J. (2021). The impact of fear of COVID-19 on job stress, and turnover intentions of frontline nurses in the community: A crosssectional study in the Philippines. Traumatology, 27(1), 52-59. https://doi.org/10.1037/trm0000294

Dewi, N. M., Januraga, P. P., \& Suarjana, K. (2020). The Relationship Between Nurse Job Satisfaction and Turnover Intention: A Private Hospital Case Study in Bali, Indonesia. Proceedings of the 4th International Symposium on Health Research (ISHR 2019). https://doi.org/10.2991/ahsr.k.200215. $\underline{117}$

Dhir, S., Dutta, T., \& Ghosh, P. (2020). Linking employee loyalty with job satisfaction using PLS-SEM modelling. Personnel Review, 49(8), 1695-1711. https://doi.org/10.1108/pr-03-20190107

Field Assessment of Pandemic Preparedness \& Response Capacity in Indonesia. (2020). 33. World Health Organization.

Global strategic directions for strenghtening nursing and midwifery 2016-2020. (2016). World Health Organization.

Gunawan, J. (2016). UNEQUAL DISTRIBUTION OF NURSES IN INDONESIA: A PERSPECTIVE FROM A NURSE. Belitung Nursing Journal, 2(1), 8-9. https://doi.org/10.33546/bnj.8

Hair, J. F., Sarstedt, M., Hopkins, L., \& G. Kuppelwieser, V. (2014). Partial least squares structural equation modeling (PLS-SEM). European Business Review, 26(2), 106-121. https://doi.org/10.1108/ebr-10-2013$\underline{0128}$

Hair, J. F., Risher, J. J., Sarstedt, M., \& Ringle, C. M. (2019). When to use and how to report the results of PLS-SEM. European Business Review, 31(1), 2-24. https://doi.org/10.1108/ebr-11-2018$\underline{0203}$

Hair, J. F., Howard, M. C., \& Nitzl, C. (2020). Assessing measurement model quality in 
PLS-SEM using confirmatory composite analysis. Journal of Business Research, 109, 101-110. https://doi.org/10.1016/i.jbusres.2019. 11.069

Hossain, M. S., Kiumarsi, S., Yahya, S., \& Hashemi, S. (2019). The effect of healthcare management and physicians' loyalty. International Journal of Healthcare Management, 14(1), 162174.

https://doi.org/10.1080/20479700.2019 .1620479

Jeffery, M. M., D’Onofrio, G., Paek, H., PlattsMills, T. F., Soares, W. E., Hoppe, J. A., Genes, N., Nath, B., \& Melnick, E. R. (2020). Trends in Emergency Department Visits and Hospital Admissions in Health Care Systems in 5 States in the First Months of the COVID19 Pandemic in the US. JAMA Internal Medicine, 180(10),

1328.

https://doi.org/10.1001/iamainternmed .2020 .3288

Kalisch, B., \& Lee, K. H. (2014). Staffing and job satisfaction: Nurses and nursing assistants. Journal of Nursing Management, 22(4), 465-471. https://doi.org/10.1111/jonm.12012

Kementerian Kesehatan Republik Indonesia. (2020). Diakses pada tanggal 20 Mei 2021:

http://sirs.yankes.kemkes.go.id/fo/

Krejcie, R. V., \& Morgan, D. W. (1970). Determining Sample Size for Research Activities. Educational and Psychological Measurement, 30(3), 607-610. https://doi.org/10.1177/001316447003 $\underline{000308}$

Kock, N., \& Hadaya, P. (2016). Minimum sample size estimation in PLS-SEM: The inverse square root and gamma-exponential methods. Information

Systems Journal, 28(1), 227-261. https://doi.org/10.1111/isj.12131

Koontz, H. (1961). The management theory jungle. Academy of Management journal, 4(3), 174-188.
Labrague, C. H. S. D. M., \& Santos, J. D. (2020). Fear of COVID-19, psychological distress, work satisfaction and turnover intention among front line nurses. https://doi.org/10.21203/rs.3.rs35366/v1

Lockhart, W. S. (2007). The Views of Physicians on Health Care Quality (dissertation). University of Saskatchewan, Saskatoon.

Lu, M., Ruan, H., Xing, W., \& Hu, Y. (2015). Nurse burnout in China: A questionnaire survey on staffing, job satisfaction, and quality of care. Journal of Nursing Management, 23(4), 440-447. https://doi.org/10.1111/ionm.12150

Mita, M., \& Maulana, M. A. (2020). Pelaksanaan Fungsi Manajemen Dan Kondisi Kerja Berhubungan Dengan Kepuasan Kerja Perawat. Window of Health : Jurnal Kesehatan, 326-335. https://doi.org/10.33368/woh.v0i0.334

Mowday, R. T., Steers, R. M., \& Porter, L. W. (1979). The measurement of organizational commitment. Journal of Vocational Behavior, 14(2), 224-247. https://doi.org/10.1016/00018791(79)90072-1

Olivia, S., Gibson, J., \& Nasrudin, R. (2020). Indonesia in the Time of Covid19. Bulletin of Indonesian Economic Studies, 56(2), 143-174. https://doi.org/10.1080/00074918.2020 .1798581

Operational Plan for the Mitigation of COVID19 in Indonesia. (2021). 65. World Health Organization

Prabowo, N. A., Apriningsih, H., Dirgahayu, P., Ardyanto, T. D., Hanafi, M., Indriani, A. T., Dyanneza, F., Kuncorowati, N. D., \& Shofiyah, L. (2020). The Decrease in Hospital Visits at Universitas Sebelas Maret Hospital Due to the Level of Stress and Fear of COVID-19. Advances in Health Sciences Research, 101-104. https://doi.org/10.2991/ahsr.k.210115. $\underline{021}$

Rayburn, J. M., \& Gayle Rayburn, L. (1991). Contingency Theory and the Impact of 
Jurnal Manajemen Dan Administrasi Rumah Sakit Indonesia

E-ISSN: 2865-6583

Vol. 5 No 2, Oktober 2021

P-ISSN: 2865-6298

New Accounting Technology in Uncertain Hospital Environments. Accounting, Auditing \& Accountability Journal, 4(2), 09513579110005257.

https://doi.org/10.1108/095135791100 $\underline{05257}$

Saralita, M., \& Ardiyanti, N. (2020). Role of Workplace Spirituality and Perceived

Organizational Support on Turnover Intention: Evidence from Private Hospital in Indonesia. KnE Social Sciences. https://doi.org/10.18502/kss.v4i6.6599

Sekaran, U., \& Bougie, R. (2016). Research methods for business: A skill building approach. John Wiley \& Sons. 